\title{
Polygenic Disease and Retinitis Pigmentosa: Albinism Exacerbates Photoreceptor Degeneration Induced by the Expression of a Mutant Opsin in Transgenic Mice
}

\author{
Muna I. Naash, ${ }^{1}$ Harris Ripps, ${ }^{1}$ Shihong Li, ${ }^{1}$ Yoshinobu Goto, ${ }^{2,3}$ and Neal S. Peachey ${ }^{2,3}$ \\ ${ }^{1}$ Department of Ophthalmology and Visual Sciences, University of Illinois College of Medicine, Chicago, Illinois 60612, \\ 2Hines VA Hospital, Hines, Illinois 60141, and ${ }^{3}$ Department of Neurology, Stritch School of Medicine, Loyola University of \\ Chicago, Maywood, Illinois 60153
}

\begin{abstract}
Expression of a mouse opsin transgene containing three point mutations (V20G, P23H, and P27L; termed VPP) causes a progressive photoreceptor degeneration that resembles in many important respects that seen in patients with autosomal dominant retinitis pigmentosa caused by a $\mathrm{P} 23 \mathrm{H}$ point mutation. We have attempted to determine whether the degree of degeneration induced by expression of the transgene is influenced by albinism, a genetically mediated recessive trait that results in a deficiency in melanin formation in pigmented tissues throughout the body. Litters of albino and pigmented mice (normal as well as transgenic) were reared in either darkness or cyclic light. Retinal structure and function were evaluated by light microscopy, electroretinography (ERG), and retinal densitometry. The data were consistent in demonstrating that at similar ages, the extent of photoreceptor degeneration was greater in transgenic albino animals than in their pigmented
\end{abstract}

counterparts. The albino VPP mice had significantly fewer cell bodies in the outer nuclear layer of the retina, a larger reduction in ERG amplitude, and a lower rhodopsin content in the rod photoreceptors. These structural and functional differences could not be attributed to the greater level of retinal illumination experienced by the albino retina under normal ambient conditions, because they persisted when pigmented and albino mice were reared in darkness from birth. Although the explanation remains unclear, our findings indicate that the rate of photoreceptor degeneration in VPP mice is adversely affected by the existence of the albino phenotype, a factor that may have implications for the counseling of human patients with retinitis pigmentosa and a familial history of other genetic disorders.

Key words: dark-rearing; albinism; pigmented mice; retinitis pigmentosa; electroretinogram; rhodopsin density; transgenic mice
Familial studies of autosomal dominant retinitis pigmentosa (ADRP) have shown that many individuals afflicted with the disease possess mutations in the rhodopsin gene that do not appear in unaffected family members (for review, see Berson, 1993). The causal relationship of some of these point mutations has been supported by studies in which a mutant rhodopsin gene is introduced into the mouse genome. Transgenic mice develop a progressive photoreceptor degeneration, whereas nontransgenic littermates do not (Olsson et al., 1992; Naash et al., 1993a,b; Sung et al., 1994; Li et al., 1995).

Naash et al. (1993a) described a line of transgenic mice that express a mutant mouse rhodopsin gene under the control of the mouse rhodopsin promoter. The transgene incorporates three point mutations near the $\mathrm{N}$ terminus. One of these is the substitution of histidine for proline at position $23(\mathrm{P} 23 \mathrm{H})$, a mutation that is seen also in human patients with ADRP (Dryja et al., 1990, 1991; Berson et al., 1991; Kemp et al., 1992). The other two

\footnotetext{
Received July 24, 1996; revised Sept. 24, 1996; accepted Sept. 27, 1996.

This work was supported by grants from The Foundation Fighting Blindness, the National Eye Institute (EY-10609, EY-06516), the Knights Templar Eye Foundation, the Arthur H. Kenney Research Fund of the Fight For Sight, the Department of Veterans Affairs, Research to Prevent Blindness, and the Charles I. Young endowment from the Lions of Illinois. We are grateful to Drs. Muayyad Al-Ubaidi and Gerald Fishman for comments on this manuscript, Jane Zakevicius, M.Sc., for invaluable services throughout the course of this study, and Mark Janowicz for photography.

Correspondence should be addressed to Muna I. Naash, Department of Ophthalmology and Visual Sciences, University of Illinois College of Medicine (m/c 648), 1855 West Taylor Street, Chicago, IL 60612.

Copyright (C) 1996 Society for Neuroscience $0270-6474 / 96 / 167853-06 \$ 05.00 / 0$
}

mutations involve the substitution of glycine for valine at position 20 (V20G) and of leucine for proline at position 27 (P27L); they were included to enhance antibody recognition of the mutant rhodopsin. Neither the V20G nor the P27L mutation has been associated with human ADRP, and different strains of mice with glycine at position 20 show no signs of retinal degeneration (Baehr et al., 1988; Al-Ubaidi et al., 1990). Mice expressing this transgene are referred to as "VPP," to identify the amino acid substitutions (Naash et al., 1993a,b, 1996; Goto et al., 1995, 1996). Histologically, VPP mice exhibit an age-related reduction in the length of the rod outer segments and a concomitant loss of photoreceptor nuclei (Naash et al., 1993a,b; 1996). These progressive changes are associated with a decrease in the rhodopsin content of the photoreceptors and a decline in the amplitude of the rod-mediated electroretinogram (Naash et al., 1993a; 1996; Goto et al., 1995). These and other functional abnormalities (see Materials and Methods) are consistent features of human ADRP induced by a $\mathrm{P} 23 \mathrm{H}$ mutation. In the human condition, however, phenotypic heterogeneity between afflicted members of the same family, in terms of both age of onset and severity of the disease, is a surprisingly frequent phenomenon (for review, see Applebury, 1992). Among the many variables that may be responsible for this diversity are gene products that interact with the expression of the defective opsin, as well as undetermined environmental conditions (Applebury, 1992).

In an attempt to identify factors that modify phenotypic expression of opsin mutations associated with retinitis pigmentosa, we are exploring the effects of polygenic disease, in which the prod- 
ucts of other gene defects may alter the photoreceptor degeneration associated with various forms of ADRP. In the present study, we examine whether there are differences in the severity of retinal degeneration between albinotic and pigmented VPP mice. It is important to stress that the retinas of albino mice that do not express the transgene seem entirely normal from birth to maturity, and there is no indication in the results of functional tests of any gross retinal abnormalities. However, because pigmented transgenic mice reared in a cyclic light environment experience a more rapid degeneration than animals reared in darkness (Naash et al., 1996), it was essential in assessing the results of the present study to distinguish between adverse effects associated with polygenic factors and those that may be attributable to the greater level of retinal illumination to which the albinotic retina is exposed. Accordingly, comparative data were obtained from animals reared in darkness as well as under routine low-intensity cyclic-light conditions.

\section{MATERIALS AND METHODS}

The transgenic VPP mouse. The mice used in these experiments were derived from matings of albino or pigmented normal breeders to albino and pigmented animals heterozygous for the VPP transgene, respectively. The normal breeders were generated from matings of C57BL/6 with FVB mice after outbreeding the rd locus; both the breeders and the VPP mice had the same genetic background. Because the transgene is passed in Mendelian fashion (Naash et al., 1993b), approximately half of the offspring in each litter were normal and half expressed the VPP mutation. Normal and transgenic mice were distinguished by PCR analysis of tail DNA, as described in detail elsewhere (Naash et al., 1993a, 1996). The phenotype of transgenic animals mimics in many respects that seen in human patients bearing a $\mathrm{P} 23 \mathrm{H}$ mutation in the opsin gene (Naash et al., 1993a,b; Goto et al., 1995; 1996). The functional defects in $\mathrm{P} 23 \mathrm{H}$ patients that are seen also in VPP mice include evidence of a gradual rod degeneration that spares cones in its initial stages (Dryja et al., 1990), an unusually slow rate of rod dark adaptation (Kemp et al., 1992), and visual sensitivity losses that can be ascribed solely to the reduced probability of quantal absorption resulting from the diminished rhodopsin content of the rods (Kemp et al., 1992). In addition, TUNEL labeling of retinal whole mounts from cyclic light-reared pigmented animals revealed a higher incidence of photoreceptor cell death in the inferior retina (Naash et al., 1996), the region most severely affected in patients with the P23H mutation (Berson et al., 1991; Stone et al., 1991; Kemp et al., 1992). A similar pattern of degeneration was seen in VPP albino animals (our unpublished observations).

The progressive degeneration observed in VPP mice is likely to reflect a direct effect of the mutant protein and not an effect of opsin overexpression (Olsson et al., 1992; Sung et al., 1994), because the total opsin mRNA measured in VPP mice is not different from that in nontransgenic littermates at early ages [postnatal day 10 (P10) and P15] before the onset of degeneration (Cheng and Naash, 1995). Moreover, the levels of mRNA transcripts for the transgene and endogenous opsin are equivalent in VPP at all ages analyzed and decline in parallel with the decrease in ONL thickness (Cheng and Naash, 1995). Thus, as in human ADRP patients, the genes for normal and mutant opsin are expressed in similar amounts in VPP mice. On the basis of previous experience with this model, we restricted our analysis to 2-month-old mice, an age at which there is clear evidence of degenerative changes and at which time functional studies can be reliably conducted (Goto et al., 1995; 1996; Naash et al., 1996).

Pregnant females were placed into one of two light conditions, and the offspring were raised from birth in that environment. The cyclic-lightreared mice were raised under a $12 \mathrm{hr}$ light/dark cycle with cage illumination of $\sim 7 \mathrm{ft}-\mathrm{c}$ during the light cycle. Dark-reared animals were raised from birth in complete darkness, and husbandry was performed under dim long-wavelength illumination. Except for light conditions, both groups of animals were treated similarly, and no differences were detected in body weight or in the general appearance of mice raised in the two environments.

Electroretinography (ERG). Electroretinograms were recorded from anesthetized mice by using procedures described previously (Goto et al., 1995; Naash et al., 1996). Mice were transported to the recording room in a light-tight box and were dark-adapted overnight. A darkadapted luminance-response function was obtained for strobe flashes $(t<1 \mathrm{msec})$ over a luminance range of -3.13 to $0.85 \log \mathrm{cd} \mathrm{sec} / \mathrm{m}^{2}$. Stimuli were presented in order of increasing luminance, and the responses to two successive flashes were averaged; the interflash interval was $30 \mathrm{sec}$ for the dimmer stimuli and $1 \mathrm{~min}$ for the more intense stimuli. At the end of a recording session, the mice were sacrificed by cervical dislocation, and the eyes were processed for histology or rhodopsin measurements. Procedures for animal care and experimentation were approved by the Animal Care Committees of the participating institutions.

Histology. Enucleated eyes were opened at the ora serrata and placed in $0.1 \mathrm{M}$ phosphate buffer, $\mathrm{pH} 7.4$, containing $2 \%$ formaldehyde, $2.5 \%$ glutaraldehyde, at $4^{\circ} \mathrm{C}$. After overnight fixation, the anterior segments were discarded, and after three rinses in phosphate buffer, the eyecups were post-fixed in $1 \% \mathrm{OsO}_{4}$ in buffer for $90 \mathrm{~min}$. After dehydration through a graded ethanol series, eyecups were infiltrated ultimately with a 1:1 mixture of Epon/Araldite; $1 \mu \mathrm{m}$ sections were stained with azureII-methylene blue. The sections were cut approximately along the horizontal meridian and passed through the optic nerve. Photoreceptor nuclei were counted in a microscopic field that was centered at $300 \mu \mathrm{m}$ from the edge of the optic nerve head and extended laterally across $70 \mu \mathrm{m}$ of the outer nuclear layer (ONL).

Rhodopsin densitometry. Measurements of rhodopsin density were obtained in situ with a microscope-based fundus reflectometer (Dowling and Ripps, 1970), which was adapted for transmission measurements through the intact eyeball of albino mice (Ostroy et al., 1992). In the case of pigmented animals, reflection measurements of the isolated flat-mounted retina were made as described previously (Goto et al., 1995). Absorbance difference spectra were derived from density differences $\left(\Delta D_{\lambda}\right)$ recorded at 24 wavelengths ranging from 420 to $700 \mathrm{~nm} ; \Delta D_{\lambda}$ represents the change in absorbance between the dark-adapted retina and the retina immediately after a $1 \mathrm{~min}$ exposure to an intense yellow (Wratten 16; 460 $\mathrm{mW} / \mathrm{mm}^{2}$ ) light (cf. Ripps and Snapper, 1974).

\section{RESULTS}

\section{Histology}

Figure 1 shows representative histological sections of retinas from normal albino mice reared in cyclic-light (Fig. $1 A$ ) or in darkness (Fig. $1 B$ ). The micrographs demonstrate that the light conditions under which the normal animals were reared had no effect on retinal histology. These images are nearly identical to those of normal pigmented animals illustrated in an earlier study (Naash et al., 1996). The remaining panels show results from VPP mice that were either albino (Fig. $1 C, D$ ) or pigmented (Fig. 1E,F), and reared either in cyclic-light (Fig. $1 C, E$ ) or in darkness (Fig. $1 D, F$ ).

Sections taken from the pigmented VPP mice (Fig. 1E,F) illustrate two of the features that had been described previously with regard to the degenerative process. (1) At two months of age, the ONL of cyclic-light-reared VPP mice is reduced in thickness to $\sim 40 \%$ of the normal, and there is a concomitant decrease in the length of the rod outer segments (cf. Naash et al., 1993a, 1996); and (2) pigmented mice reared in darkness display a less severe degeneration than age-matched animals raised in typical cyclic-light conditions (cf. Naash et al., 1996). A similar situation obtains for the albino VPP mice. Comparing the micrograph in Figure $1 C$ with $1 D$ again shows that the preservation of visual cells is greater in dark-reared than in cyclic-light-reared transgenic mice.

It is important to note, however, that regardless of the lighting conditions under which the animals were reared, the degenerative changes are more pronounced in albino than in pigmented VPP mice. Fewer receptor nuclei are seen in the dark-reared albino retina (Fig. 1D) than in the aged-matched, dark-reared pigmented animal (Fig. $1 F$ ), and the photoreceptors of cyclic-lightreared albinos are almost completely devoid of outer segments 
Cyclic-light
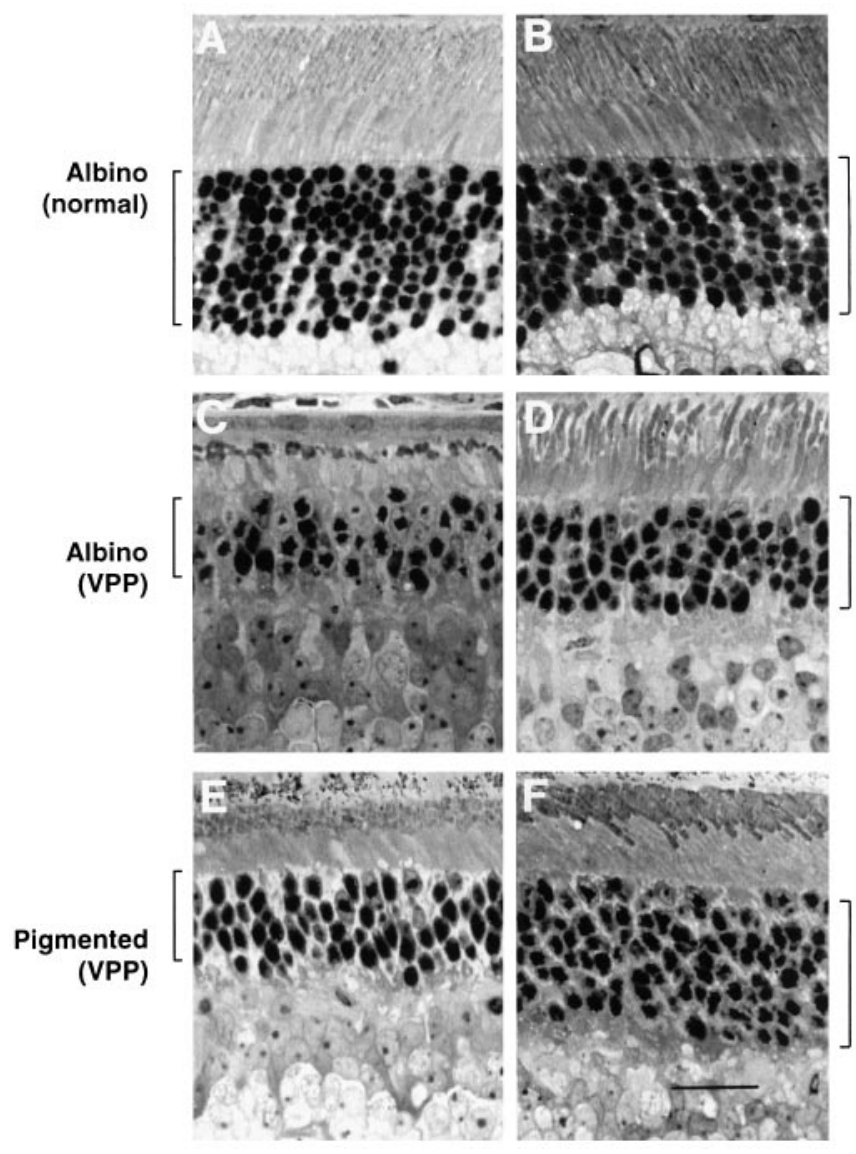

Figure 1. Representative histological sections of retinas from normal and transgenic mice. $A, B$, Sections taken from normal albino mice reared in cyclic light $(A)$ or darkness $(B)$. No differences were observed between normal albino and pigmented animals regardless of light conditions. The remaining sections were taken from VPP mice that were either albino $(C$, $D$ ) or pigmented $(E, F)$. Under both lighting conditions, the thickness of the ONL was greater in the retinas of pigmented transgenic mice. Scale bar, $20 \mu \mathrm{m}$. Brackets indicate the extent of the ONL.

(Fig. 1C), whereas those of light-reared pigmented VPP mice show a greater retention of outer segment membrane (Fig. 1E). The histological data are quantified in Figure 2, where the bar graphs illustrate the average $( \pm$ SEM) number of cell bodies present in the ONL. Under both environmental light conditions, the retinas of albino mice had significantly fewer photoreceptor nuclei than their pigmented counterparts. Clearly, the observation that albino VPP mice reared in darkness from birth exhibit a more severe degeneration than pigmented animals reared under similar conditions indicates that differences in the degree of degeneration cannot be attributed to a disparity in the level of retinal illumination.

\section{ERG}

The ERG recordings from albino and pigmented VPP mice were consistent with the histological findings. Figure $3 A$ shows typical recordings made in response to the highest intensity stimulus flash $\left(0.85 \mathrm{log} \mathrm{cd} \mathrm{sec} / \mathrm{m}^{2}\right)$ from normal mice (top waveforms), pigmented VPP mice (middle waveforms), and albino VPP mice (bottom waveforms). Although there is evi-

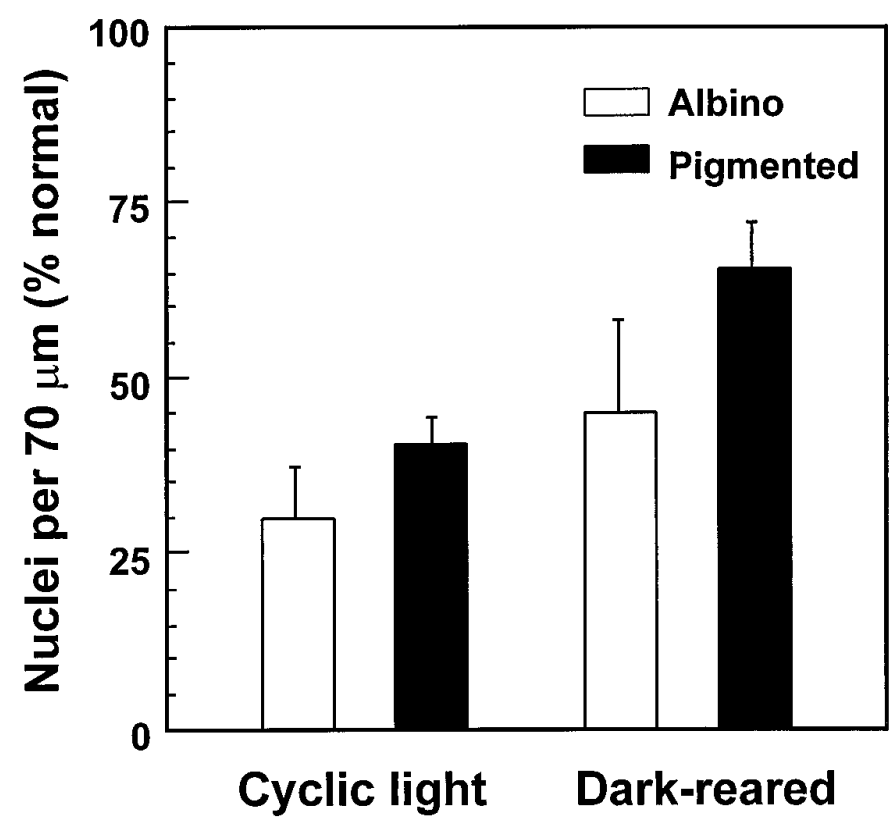

Figure 2. Number of photoreceptor nuclei counted within a $70 \mu \mathrm{m}$ microscopic field that was centered at $300 \mu \mathrm{m}$ from the edge of the optic nerve head. All values are expressed as a percentage of the values obtained from normal littermates; each bar represents the mean ( \pm SEM) of three to six measurements. Both the thickness and the cellular content of the ONL were significantly greater in pigmented than in albino VPP mice (all $p<0.05)$.

dence of rod degeneration in both strains of VPP mice, the decrement in response amplitude is greater in the albino mice. These observations are summarized in Figure $3 B$ : the ERG a-wave was larger in pigmented VPP mice than in their albino counterparts. Again it should be emphasized that the loss of response amplitude was significantly greater in dark-reared albino animals; i.e., differences in retinal illumination cannot account for the observed differences between albino and pigmented transgenic animals.

\section{Rhodopsin densitometry}

Rhodopsin measurements provided further confirmation of the results shown in the previous sections. Figure 4 presents average density difference spectra obtained from the retinas of pigmented and albino VPP mice reared under cyclic light (Fig. $4 A$ ) or in darkness (Fig. $4 B$ ). Because the quantitative data obtained with the different spectrophotometric methods used to analyze albino and pigmented retinas are not strictly comparable, the results for the VPP animals in each case are plotted relative to the difference spectra obtained from normal littermates (dashed line). When graphed in this fashion, it is apparent that the loss of rhodopsin in the retinas of albino VPP mice was significantly greater than in pigmented animals, and that this difference obtains regardless of the conditions of illumination in which the mice were reared.

\section{DISCUSSION}

The results of this study indicate that the progressive photoreceptor degeneration caused by the mutant VPP transgene is exacerbated by coexpression of the genetic aberration that causes albinism. Compared with pigmented transgenic animals, VPP albino 
A

cyclic

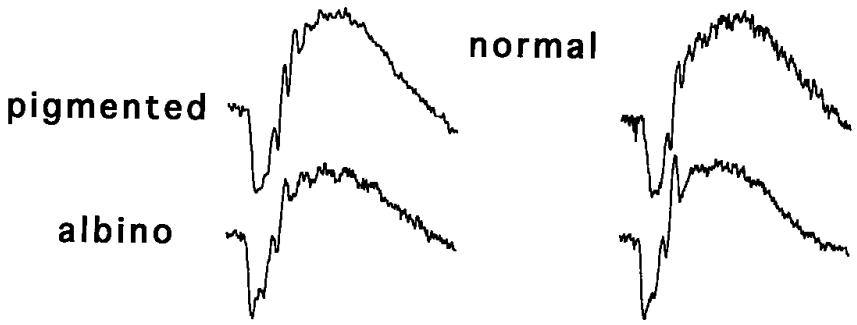

pigmented

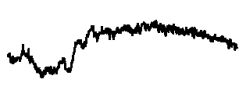

VPP

albino
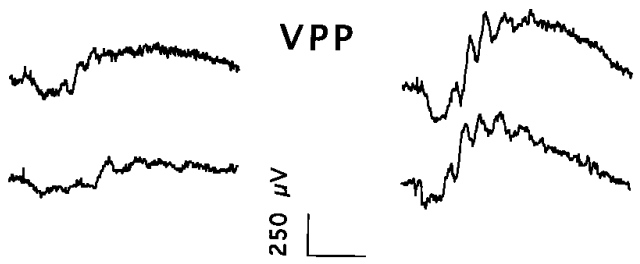

$40 \mathrm{msec}$



Figure 3. A, Electroretinograms obtained in response to a high intensity strobe flash $\left(0.85 \log \mathrm{cd} \mathrm{sec} / \mathrm{m}^{2}\right)$ presented to the dark-adapted eye from normal mice (top traces) and VPP mice (bottom traces). B, Amplitude of the ERG a-wave. All values are expressed as a percentage of the values obtained from normal littermates; each bar represents the mean $\pm \mathrm{SEM}$ of 15-23 measurements. Responses were significantly greater in pigmented than in albino VPP mice (all $p<0.001$ ).

mice had a more severe degeneration as measured by the survival of photoreceptor cells, the retention of electroretinal sensitivity, and the rhodopsin content of the retina.

Figure 4. Rhodopsin density difference spectra obtained from albino and pigmented VPP mice. Mice were reared under cyclic light $(A)$ or in complete darkness $(B)$. Each set of data is plotted as a percentage of the values obtained from normal littermates and represents the mean of 10-13 measurements; the dashed lines indicate the normal difference spectrum. For both lighting conditions, the rhodopsin content of the pigmented VPP retina was significantly greater than in albino VPP mice (all $p<0.001$ ).
Although at no time during the course of these experiments were the VPP mice exposed to light intensities that are known to induce photic damage in normal animals (Organisciak and

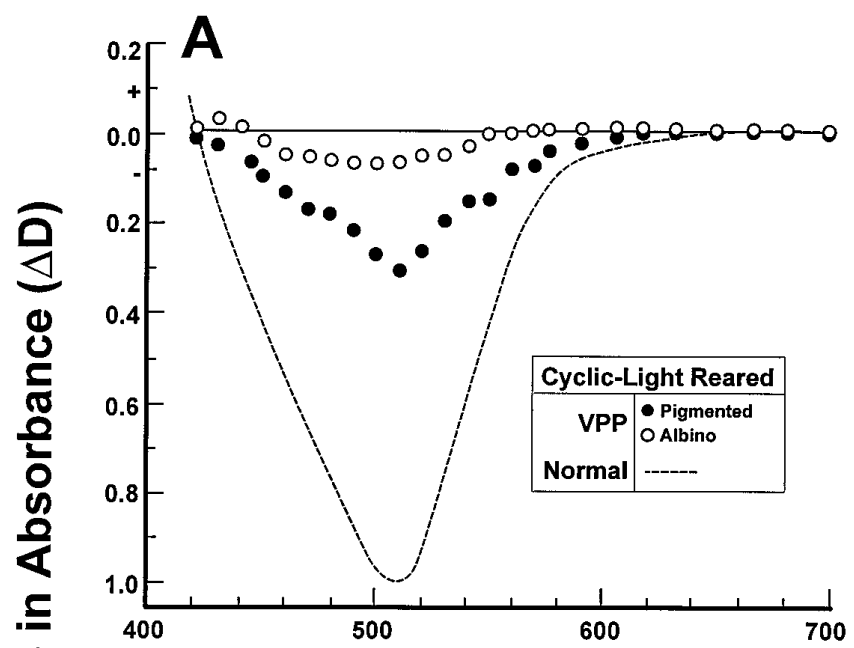


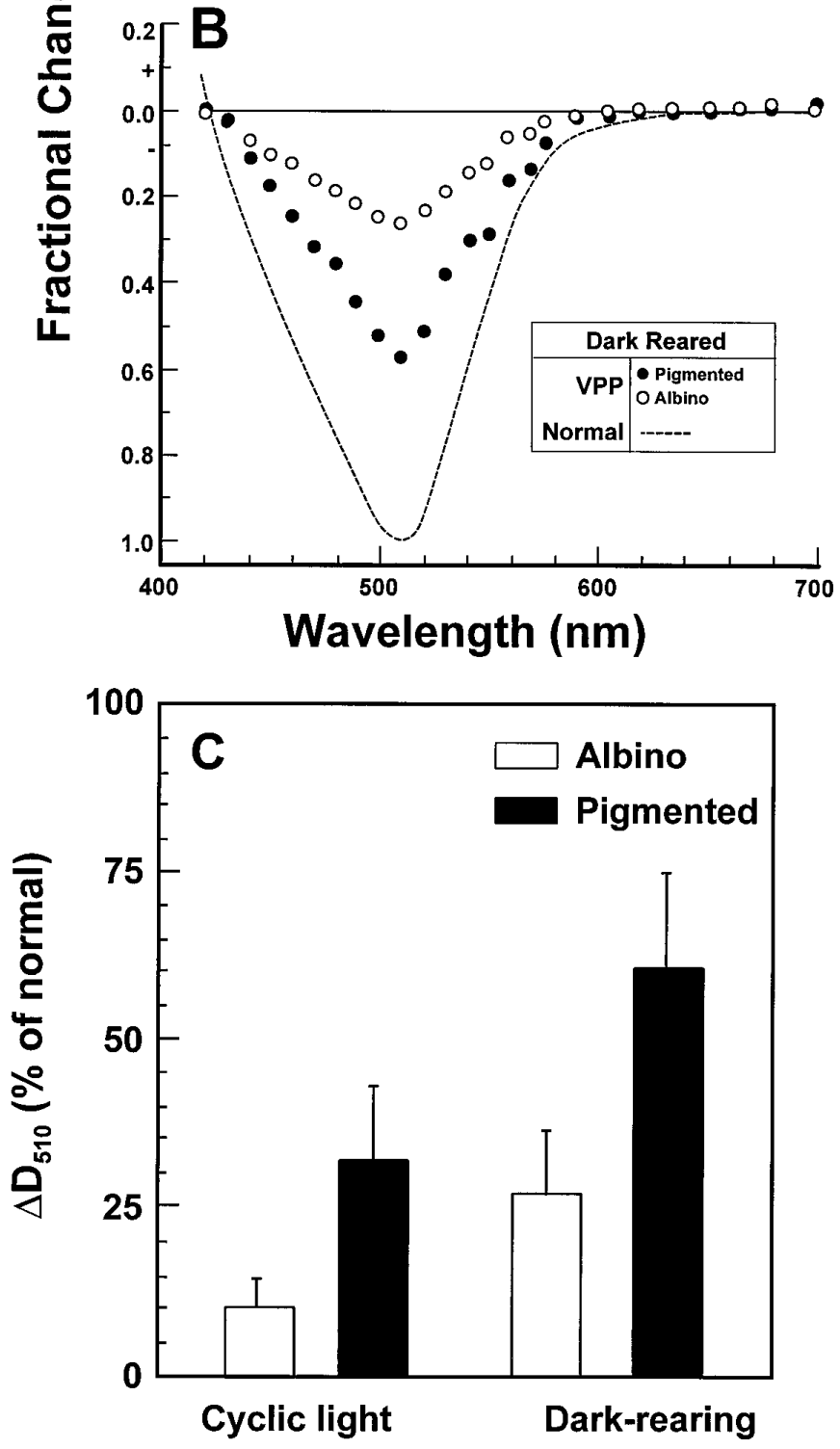
Winkler, 1994), it was important to establish that the differences between the two strains did not result from the inherently greater level of illumination to which the albino retina was exposed. The retinas of genetically inbred strains of albino mice have been shown to be particularly susceptible, in varying degree, to photic injury induced by prolonged exposure to moderately intense levels of ambient illumination (LaVail et al., 1987; Naash et al., 1989); ocular pigmentation protects against light damage primarily by reducing the effective retinal irradiance (Rapp and Williams, 1980). However, results obtained from mice reared from birth in darkness clearly preclude the possibility that this environmental factor was the cause of the more severe degeneration seen in albino VPP mice as compared with pigmented mice bearing the transgene. Although dark-rearing retarded the degeneration in both groups of mice, the differences between albino and pigmented mice were nevertheless retained.

The genetic pathway by which albinism affects the disease process induced by a mutation in opsin has yet to be identified, but it has been suggested that the phenotypic heterogeneity that exists among retinitis pigmentosa patients with the same opsin mutation (Berson et al., 1991; Heckenlively et al., 1991) may result from some aspect of the complex interaction of the point mutation with other gene products (Applebury, 1992). Interestingly, this type of reaction may not require a gene product that is itself associated with a degenerative process. Several cases of retinitis pigmentosa resulting from mutations in two unlinked photoreceptor-specific genes, ROM1 and peripherin/RDS, were reported recently (Kajiwara et al., 1994). Because only double heterozygotes develop retinitis pigmentosa, and it is not known whether an abnormal phenotype would result from homozygosity for either of these alleles, the authors refer to the condition as a form of "digenic" disease.

In the present study, the interaction involves oculocutaneous albinism, an autosomal recessive disorder caused by a deficiency in tyrosinase, the enzyme that catalyzes melanin formation. The genetic defect is expressed early in embryogenesis, resulting in the absence of melanin granules and generalized hypopigmentation (Carr and Siegel, 1979; Kuwabara, 1979). Many visual pathway defects are associated with albinism in man and animals (cf. Dräger and Olsen, 1980; Guillery, 1986), and it has been suggested that the loss of the $\mathrm{Ca}^{2+}$-buffering capacity of melanin may be responsible for some of these neurological aberrations (Dräger, 1985). Moreover, the absence of melanin in the normally pigmented retinal epithelium can exert a deleterious effect on photoreceptor development (Stone et al., 1978; Choudhury, 1981; Kinnear et al., 1985), which in turn may increase the severity of a disease in which the normal disk renewal process is already compromised (Ripps, 1982; Sung et al., 1994).

In sum, our results stress the importance of considering the potential influence of other genetic defects, as well as environmental factors, in counseling patients with retinitis pigmentosa. Although the phenotypic manifestation of polygenic disease is difficult to assess, it is increasingly evident that correlative information culled from family history as to the degree of heterogeneity among afflicted family members may help eventually to identify the elements that contribute to this diversity.

\section{REFERENCES}

Al-Ubaidi MR, Pittler SJ, Champagne MS, Triantafyllos JT, McGinnis JF, Baehr W (1990) Mouse opsin: gene structure and molecular basis of multiple transcripts. J Biol Chem 265:20563-20569.

Applebury ML (1992) Variations in retinal degeneration. Curr Biol 2:113-115.
Baehr W, Falk JD, Bugra K, Triantafyllos JT, McGinnis JF (1988) Isolation and analysis of the mouse opsin gene. FEBS Lett 238:253-256.

Berson EL (1993) Retinitis pigmentosa. Invest Ophthalmol Vis Sci 34:1659-1676.

Berson EL, Rosner B, Sandberg MA, Dryja TP (1991) Ocular findings in patients with autosomal dominant retinitis pigmentosa and a rhodopsin gene defect (pro-23-his). Arch Ophthalmol 109:92-101.

Carr RE, Siegel IM (1979) The retinal pigment epithelium in ocular albinism. In: The retinal pigment epithelium (Zinn KM, Marmor MF, eds), pp 58-62. Cambridge, MA: Harvard UP.

Cheng T, Naash MI (1995) Quantitative analysis of mRNA levels of the transgenic and endogenous opsin genes in retinas of transgenic mice. ARVO Abstracts. Invest Ophthalmol Vis Sci 36:S273.

Choudhury BP (1981) Ganglion cell distribution in the albino rabbit's retina. Exp Neurol 72:638-644.

Dowling JE, Ripps H (1970) Visual adaptation in the retina of the skate. J Gen Physiol 56:491-520.

Dräger UC (1985) Calcium binding in pigmented and albino eyes. Proc Natl Acad Sci USA 82:6716-6720.

Dräger UC, Olsen JF (1980) Origins of crossed and uncrossed retinal projections in pigmented and albino mice. J Comp Neurol 191:383-412.

Dryja TP, McGee TL, Reichel EL, Hahn LB, Cowley GS, Yandell DW, Sandberg MA, Berson EL (1990) A point mutation of the rhodopsin gene in one form of retinitis pigmentosa. Nature 343:364-366.

Dryja TP, Hahn LB, Cowley GS, McGee TL, Berson EL (1991) Mutation spectrum of the rhodopsin gene among patients with autosomal dominant retinitis pigmentosa. Proc Natl Acad Sci USA 88:9370-9374.

Goto Y, Peachey NS, Ripps H, Naash MI (1995) Functional abnormalities in transgenic mice expressing a mutant rhodopsin gene. Invest Ophthalmol Vis Sci 36:62-71.

Goto Y, Peachey NS, Ziroli NE, Seiple WH, Gryczan C, Pepperberg DR, Naash MI (1996) Rod phototransduction in transgenic mice expressing a mutant opsin gene. J Opt Soc Am [A] 13:577-585.

Guillery RW (1986) Neural abnormalities in albinos. Trends Neurosci 9:364-367.

Heckenlively JR, Rodriguez JA, Daiger SP (1991) Autosomal dominant sectoral retinitis pigmentosa: two families with transversion mutation in codon 23 of rhodopsin. Arch Ophthalmol 109:84-91.

Kajiwara K, Berson EL, Dryja TP (1994) Digenic retinitis pigmentosa due to mutations at the unlinked peripherin/RDS and ROM1 loci. Science 264:1604-1608.

Kemp CM, Jacobson SG, Roman AJ, Sung C-H, Nathans J (1992) Abnormal rod dark adaptation in autosomal dominant retinitis pigmentosa with proline-23-histidine rhodopsin mutation. Am J Ophthalmol 113:165-174.

Kinnear PE, Jay B, Witkop CJ (1985) Albinism. Surv Ophthalmol 30:75-101.

Kuwabara T (1979) Species differences in the retinal pigment epithelium. In: The retinal pigment epithelium (Marmor MF, Zinn KM, eds), pp 58-62. Cambridge, MA: Harvard UP.

LaVail MM, Gorrin GM, Repaci MA, Thomas LA, Ginsberg HM (1987) Genetic regulation of light damage to photoreceptors. Invest Ophthalmol Vis Sci 28:1043-1048.

Li T, Franson WK, Gordon JW, Berson EL, Dryja TP (1995) Constitutive activation of phototransduction by K296E opsin is not a cause of photoreceptor degeneration. Proc Natl Acad Sci USA 92:3551-3555.

Naash MI, LaVail MM, Anderson RE (1989) Factors affecting the susceptibility of the retina to light damage. In: Inherited and environmentally induced retinal degenerations (LaVail MM, Anderson RE, Hollyfield JG, eds), pp 513-522. New York: Alan R. Liss.

Naash MI, Hollyfield JG, Al-Ubaidi MR, Baehr W (1993a) Stimulation of human autosomal dominant retinitis pigmentosa in transgenic mice expressing a mutated murine opsin gene. Proc Natl Acad Sci USA 90:5499-5503.

Naash MI, Al-Ubaidi MR, Hollyfield JG, Baehr W (1993b) Stimulation of autosomal dominant retinitis pigmentosa in transgenic mice. In: Retinal degenerations (Hollyfield JG, Anderson RE, LaVail MM, eds), pp 202-210. New York: Plenum.

Naash MI, Peachey NS, Li Z-Y, Gryczan CC, Goto Y, Blanks J, Milam AH, Ripps H (1996) Light-induced acceleration of photoreceptor degeneration in transgenic mice expressing mutant rhodopsin. Invest Ophthalmol Vis Sci 37:775-782. 
Olsson JE, Gordon JW, Pawlyk BS, Roof D, Hayes A, Molday RS, Mukai S, Cowley GS, Berson EL, Dryja TP (1992) Transgenic mice with a rhodopsin mutation (Pro23His): a mouse model of autosomal retinitis pigmentosa. Neuron 9:815-830.

Organisciak DT, Winkler BS (1994) Retinal light damage: practical and theoretical considerations. Progress in retinal and eye research, Vol 13 (Osborne NN, Chader GJ, eds), pp 1-29. London: Elsevier Science Ltd.

Ostroy SE, Friedmann AL, Gaitatzes CG (1992) Extracellular glucose dependence of rhodopsin regeneration in excised mouse eye. Exp Eye Res 55:419-423.

Rapp LM, Williams TP (1980) The role of ocular pigmentation in protecting against retinal light damage. Vision Res 20:1127-1131.
Ripps H (1982) Night blindness revisited; from man to molecules. Invest Ophthalmol Vis Sci 23:588-609.

Ripps H, Snapper A (1974) Computer analysis of photochemical changes in the human retina. Comput Biol Med 4:107-122.

Stone J, Rowe MH, Campion JE (1978) Retinal abnormalities in the Siamese cat. J Comp Neurol 180:773-782.

Stone EM, Kimura AE, Nichols BE, Khadivi P, Fishman GA, Sheffield VC (1991) Regional distribution of retinal degeneration in patients with the proline to histidine mutation in codon 23 of the rhodopsin gene. Ophthalmology 98:1806-1813.

Sung C-H, Makino C, Baylor D, Nathans J (1994) A rhodopsin gene mutation responsible for autosomal dominant retinitis pigmentosa results in a protein that is defective in localization to the photoreceptor outer segment. J Neurosci 14:5818-5833. 